\title{
Review: chlorpromazine reduces relapse but increases adverse events in schizophrenia
}

\author{
Thornley B, Adams CE, Awad G. Chlorpromazine versus placebo for those with schizophrenia. In: The Cochrane Library, issue 1. \\ Oxford: Update Software, 1988.
}

\section{Question}

In schizophrenia, to what extent does chlorpromazine reduce symptoms, relapse, and discontinuation of medication, and how frequent are the most common adverse events?

\section{Data sources}

Studies were identified by searching Biological Abstracts, Cochrane Schizophrenia Group's Register, The Cochrane Library, EMBASE, Medline, PsycLIT, and SCISEARCH; by scanning the bibliographies of identified articles; and by contacting pharmaceutical companies and authors of trials.

\section{Study selection}

Studies were selected if they were randomised controlled trials investigating the effectiveness of chlorpromazine compared with placebo or no treatment in patients with schizophrenia.

\section{Data extraction}

Data were extracted on patient characteristics, drug dose, and primary outcomes of interest: death, relapse, overall improvement, discontinuation of medication, and adverse events.

\section{Main results}

A meta-analysis was done. 76 reports (referring to 42 studies) met the selection criteria. No death was reported in any study. The table shows the main outcomes.

\section{Conclusion}

In patients with schizophrenia, chlorpromazine reduces relapse, leads to greater global improvement, and less discontinuation of medication but with a greater risk of adverse effects.

Sources of funding: NHS Executive Anglia and Oxford R E D Directorate UK.

For article reprint: Mr B Thornley, Research Assistant, The Cochrane Schizophrenia Group, Summertown Pavilion, Middle Way, Summertown, Oxford OX2 7LG, UK. Fax +44 (0)1865 316023. Abstract and commentary also published in Evidence-Based Medicine.

Chlorpromazine v placebo or no treatment in schizophrenia*

\begin{tabular}{|c|c|c|c|c|}
\hline \multirow[b]{2}{*}{ Outcome } & \multicolumn{2}{|c|}{ Weighted event rates } & \multirow[b]{2}{*}{$R R R(95 \% C I)$} & \multirow[b]{2}{*}{$N N T(C I)$} \\
\hline & Chlorpromazine & Control & & \\
\hline Relapse (6 months- 2 years) & $40 \%$ & $71 \%$ & $43 \%$ (33 to 52$)$ & $4(3$ to 5$)$ \\
\hline Relapse ( $2-5$ years) & $55 \%$ & $83 \%$ & $35 \%(25$ to 44$)$ & $4(3$ to 6$)$ \\
\hline Outcome & Chlorpromazine & Control & $R B I(95 \% C I)$ & $N N T(C I)$ \\
\hline Global improvement $(0-8$ weeks $)$ & $55 \%$ & $37 \%$ & $63 \%(38$ to 94$)$ & $6(5$ to 9$)$ \\
\hline Global improvement (9 weeks-6 months) & $30 \%$ & $13 \%$ & $137 \%(84$ to 207$)$ & $6(5$ to 8$)$ \\
\hline Outcome & Chlorpromazine & Control & $R R I(95 \% C I)$ & $N N H(C I)$ \\
\hline Sedation & $28 \%$ & $13 \%$ & $133 \%(82$ to 197$)$ & $7(6$ to 9$)$ \\
\hline Acute movement disorders (dystonia) & $6 \%$ & $2 \%$ & $214 \%(30$ to 659$)$ & $29(16$ to 131$)$ \\
\hline Parkinsonism & $12 \%$ & $7 \%$ & $101 \%(50$ to 169$)$ & $21(14$ to 47$)$ \\
\hline Fits & $5 \%$ & $2 \%$ & $211 \%(5$ to 818$)$ & 30 (20 to 67$)$ \\
\hline Lowered blood pressure & $16 \%$ & $8 \%$ & $113 \%(52$ to 198$)$ & $13(9$ to 24$)$ \\
\hline Weight gain & $41 \%$ & $9 \%$ & $351 \%(118$ to 832$)$ & $4(3$ to 6$)$ \\
\hline Photo-sensitivity & $15 \%$ & $3 \%$ & $504 \%$ (222 to 1032$)$ & $9(7$ to 12$)$ \\
\hline Eye opacity or pigment problem & $20 \%$ & $7 \%$ & $204 \%(85$ to 400$)$ & $8(6$ to 13$)$ \\
\hline Dry mouth & $6 \%$ & $1 \%$ & $334 \%$ ( 75 to 979$)$ & $21(14$ to 41$)$ \\
\hline
\end{tabular}

*Abbreviations defined in glossary; RRR, RBI, RRI, NNT, NNH, and CI calculated from data in article.

\section{Commentary}

The conclusions of this careful review are reassuring in that they provide support for a prevailing clinical view regarding the risks and benefits of chlorpromazine. The mean dose used in the studies, just above 500 $\mathrm{mg} /$ day, is around the middle of the optimum range for antipsychotic medication, as identified by Baldessarini et al. The details of this review are of current relevance given the continued widespread use of chlorpromazine worldwide. The majority of the clinical trials selected were, however, conducted between 1960 and 1980 , and any reservations about the conclusions relate to the limitations of such studies. The definition of relapse would have varied between studies, often reflecting admission to hospital rather than any standard criterion level of symptom severity. Admission to hospital itself is potentially a powerful psychosocial intervention and this may be relevant to the relatively high placebo response noted. Outcome in terms of behaviour relates predominantly to disturbed and uncooperative behaviour. Although this is of direct relevance to the treatment of acute schizophrenia, it is less generalisable to social behaviour and functioning in the community.

There are several issues relating to the comprehensiveness of the data regarding side effects. For example, sexual side effects are not mentioned. The assessment of akathisia was often limited to a single item on a rating scale for extrapyramidal side effects (EPS), so its apparent low incidence relative to parkinsonism may be misleading. One indirect measure of the frequency and severity of EPS is the proportion of patients who receive concomitant anticholinergic agents. This information was not extracted, although it is also relevant to the broader interpretation of the side effect data. ${ }^{2}$ The subjective burden of side effects was rarely assessed in studies of that era, although this has become an area of increasing interest, particularly its influence on compliance. Nevertheless, Thornley et al suggest that sleepiness due to chlorpromazine would not always be welcomed by those with schizophrenia. Sedation, although generally regarded as an adverse effect, may be of benefit in the initial stages of treatment of patients who are acutely disturbed. However, the suggestion in this review that sedation and other side effects might erode the ability of patients to make informed decisions is purely speculative and should be balanced by the reduction in reality distortion that can accompany treatment with chlorpromazine.

Thomas RE Barnes, MD, FRCPsych Imperial College School of Medicine London, UK

1 Baldessarini RJ, Cohen BM, Teicher MH. Arch Gen Psychiatry 1998;45:79-91.

2 Barnes TRE, McPhillips MA. CNS Drugs 1996; 6:315-30. 